\title{
Entre a ubiquidade e a convergência midiáticas: comunicação e inovação no futebol do Sport Club Internacional
}

BETWEEN UBIQUITY AND MEDIA CONVERGENCE: COMMUNICATION AND INNOVATION IN THE FOOTBALL 1

\section{Beatriz Correa Pires Dornelles}

Professora doutora titular do Programa de Pós-Graduação em Comunicação da Pontifícia Universidade Católica do Rio Grande do Sul. Possui pós-doutorado pela Universidade Fernando Pessoa (Porto/Portugal).

E-mail: biacpd@pucrs.br

\section{Marcel Neves Martins}

Doutorando em Comunicação Social pela Pontifícia Universidade Católica do Rio Grande do Sul. E-mail: neves.marcel@gmail.com

Recebido em 28 de maio de 2015. Aprovado em 6 de agosto de 2015.

\section{Resumo}

Este artigo tem como objetivo abordar o uso da tecnologia no esporte para fins de análise, aperfeiçoamento e aprimoramento de atletas, como no caso do Sport Club Internacional, de Porto Alegre (RS), que utiliza um conjunto de softwares para análise de jogadores com potencial de contratação pelo clube e de um dispositivo (colete) com GPS para a análise de desempenho de seus atletas durante os treinamentos. Sendo assim, a partir de pesquisa documental e bibliográfica buscamos compreender a lógica de funcionamento desses dispositivos no contexto da digitalização e virtualização do mundo atual.

Palavras-chave: Comunicação. Inovação. Tecnologia.

\section{Abstract}

The article aims to address the use of technology in sport for analysis, improvement and enhancement of athletes, as it is with the Sport Club 
Internacional, of Porto Alegre (RS), which uses a software suite to analyze the players with potential for hiring by the club and a device (vest) with GPS for performance analysis of their athletes during training. Thus, from documentary and bibliographical research, we aim to understand the operating logic of these devices in the context of digitalization and virtualization of today's world.

Keywords: Communication. Innovation. Technology.

\section{Introdução}

A edição de número 100 da Revista do Inter, do Sport Club Internacional, de Porto Alegre, Rio Grande do Sul, apresenta os novos equipamentos utilizados pelo departamento de futebol do clube para aprimoramento tanto da análise de atletas, que podem vir a ser contratados, como melhora das condições de análise do desempenho de seus atletas durante os treinamentos. Para o esquadrinhamento do perfil dos possíveis futuros jogadores do clube e que têm chances de ser contratados, o Centro de Análise e Prospecção de Atletas do Internacional (CAPA) utiliza de forma integrada um conjunto de dispositivos que inclui computadores, notebooks, softwares e aparelhos de televisão. Já para o trabalho com os atletas do clube, foram adquiridos para a fisiologia coletes com sistema integrado de GPS que monitoram todas as movimentações dos profissionais dentro de campo.

A questão da inovação aparece claramente no investimento promovido pela instituição para adquirir novos aparelhos informáticos. Em relação à análise de jogadores para contratação, a inovação está presente no fato de que não se contrata mais apenas pelo oferecimento de atletas por empresários ou pelo necessário deslocamento de observadores do clube para vê-los em ação nos jogos de futebol mundo afora, mas conta-se com dispositivos que permitem conhecer melhor o jogador a partir de um "raio x" que se faz dele pelo uso de dispositivos de informação e comunicação; agora, o clube vai até o jogador de outro modo, ou melhor, é o atleta que vem até a instituição pelos materiais coletados com suas performances em campo.

Quanto ao uso de um colete com sistema de GPS acoplado em combinação com um software em um notebook que recebe as informações transmitidas, a inovação pode ser percebida nos avanços tecnológicos para o recolhimento desses dados com os resultados das movimentações de campo. No início, os fisiologistas usavam um cronômetro, depois passaram ao uso de uma espécie de relógio de pulso em cada atleta, evoluindo agora para o uso dos coletes com sensores que captam e registram o desempenho dos atletas. É uma inovação que acontece 
tanto em termos tecnológicos quanto para o próprio mundo do futebol podendo aprimorar assim a avaliação de seus profissionais mediante o uso de novas tecnologias de comunicação.

Nesse contexto, este artigo se divide em três partes. Na primeira parte fizemos um exercício epistemológico para abordar a comunicação a partir de artigos apresentados em congressos da Compós, especialmente no GT de Epistemologia da Comunicação. Na segunda parte abordamos as lógicas de realização dos dispositivos do CAPA, do Sport Club Internacional. Já na terceira parte, também discutimos o uso de tecnologias de comunicação por esse clube, especificamente no uso desse colete com GPS pelos jogadores do Inter.

\section{A comunicação como tentativa}

A comunicação, pensamos, deve ser percebida como processo que configura o conjunto das manifestações dos indivíduos e das coletividades ao longo da história, não apenas impulsionando outros processos - artísticos, políticos, culturais, filosóficos, científicos, econômicos - que afloram nas criações, invenções e descobrimentos como se faz presente nesses atos para que eles aconteçam em sua excelência. De acordo com Machado (2001, p. 8), "dentro de uma certa tradição filosófica, onde é possível situar, sobretudo, o pensamento de Santo Agostinho, Platão, Aristóteles, Cícero e Quintilhano, a comunicação é produto da significação das mensagens".

Machado ressalta que "a comunicação só pode ser pensada como resultado de um circuito de relações onde a informação é o impulso e a significação, a meta" (Ibidem, p. 8). De fato, há um circuito de relações para que o processo comunicativo se estabeleça, no entanto, o impulso está, justamente por haver esse circuito, na relação de quem comunica com o universo ao qual está imerso. Assim, a informação também poderia ser percebida como a meta, de modo que o informar seria o objetivo em meio a meta da significação. Dessa forma, um fim estaria contido no outro.

Há uma tecnicidade na comunicação, na medida que pela técnica a comunicação acontece e é determinada. A técnica não apenas presentifica o processo comunicativo como dá o tom da sua forma final, do modo como será percebido e apreendido no contexto em que se realiza. Contudo não se pode pensar que a técnica condensa a comunicação, de modo a torná-la fechada para quem participa do processo, principalmente, para quem está na condição de receptor. A técnica modula e age na codificação daquilo que se quer fazer perceber, mas não condiciona o produto final da comunicação.

Nesse contexto, percebemos que toda e qualquer ação comunicativa em desenvolvimento é tentativa em seu processo e sua finalidade. Tentativa porque a comunicação não se esgota em si mesma, sendo um processo em que a intenção vale como propósito para 
se atingir a determinado fim, aquele mesmo do comunicar. Braga (2010) dá ênfase à palavra "tentativa" porque não enxerga certeza de resultados nos processos comunicacionais, indicando que a comunicação não é controlável, a despeito das intenções e objetivos de seus participantes.

Dois ângulos caracterizam a perspectiva de que a comunicação é tentativa. Pelo primeiro ângulo, os episódios comunicacionais são probabilísticos - significando que alguma coisa pode acontecer. Por este aspecto, então, devemos perceber diferentes graus de probabilidade, desde uma efetiva ocorrência de resultados até uma baixa ou nula probabilidade [...] Pelo segundo ângulo, os processos comunicacionais são aproximativos - correspondendo a comportarem maior ou menor precisão (dentro de diferentes critérios, eventualmente internos, de "precisão") (Ibidem, p. 6).

Assim, o que caracteriza ainda a comunicação como tentativa é a capacidade de influência entre as partes do processo comunicativo. A influência é por si só tentativa, na medida que a situação de comunicação estabelecida pode ser uma resposta a uma ação anterior. Há uma espécie de circularidade que se estabelece na comunicação tentativa porque cada parte presente do processo vai procurar influenciar tentativamente, logo por aproximação, a outra parte - e com toda a carga de probabilidade de se atingir a efetividade desejada no ato de comunicação. Em meio à tentativa da comunicação reside a capacidade de não entendimento, ou do difícil entendimento, que se deve à sutileza da comunicação: "a comunicação é algo muito mais sutil e de difícil entendimento, porque ela não está apenas na esfera do discurso (nomeando-a nós a aprisionamos e assim a esvaziamos), mas no campo do sentir" (SANTOS, 2007, p. 6).

A problemática do entendimento está relacionada ao fato da comunicação ser um sistema fechado ou aberto. Sampaio (2001) com base em Niklas Luhmann aponta a comunicação como sistema fechado completo, pois é capaz de produzir os componentes a partir dos quais ela existe: "Nesse sentido é qualificada como um sistema autopoiético, no sentido de autoelaboração, como um sistema que é capaz de especificar não apenas seus elementos, mas suas próprias estruturas" (SAMPAIO, 2001, p. 16). Ainda, a comunicação autopoiética definiria também a própria percepção do seu sentido, como forma de engendramento de uma significação que lhe constitui.

Enquanto sistema fechado, a comunicação seria improvável, conforme o que Sampaio (2001) assegura sobre o pensamento de Luhmann. A improbabilidade residiria no fato de cada indivíduo possuir memória e consciência individualizadas. O fator do improvável na comunicação se relaciona justamente ao seu caráter tentativo, com probabilidade variável de êxito. De maneira lógica, a comunicação é apenas possível para aqueles que se 
encontram na mesma situação de comunicação, sendo improvável de acontecer para quem não se encontra em tal. Nesse sentido, a ação comunicativa contempla quem pertence ao mesmo contexto ou, tentativamente, a quem potencialmente pode vir a participar dele.

Nada é certo quando se trata de comunicação. Não há como garantir o sucesso de uma comunicação, muito menos dá-la como certa. O caráter tentativo, que é sua característica, e o componente da probabilidade no processo geram possibilidades de incerteza no ato de comunicação, quanto à efetividade, quanto à capacidade de se atingir com eficácia o objetivo do comunicar. De acordo com Ferrara (2006, p. 8) "todo vínculo comunicativo flutua em um contínuo semiótico feito de falível incerteza e de definições provisórias". As definições provisórias assim são dadas porque a comunicação não se esgota no ato de quem comunica, mas é definida no momento da recepção pelo outro que toma lugar na situação de comunicação e age nela com seu mapa cognitivo-intelectual-mental de mundo.

É nesse contexto que o sucesso da comunicação está dado, e ao ser dependente dessa negociação de sentidos e desse intercâmbio de signos, o ato comunicativo emerge na sua performatividade de modo a se realizar com diferentes graus de valor: de valor alto ou baixo. Nem sempre é clara e ideal, mas pode ser conflitiva, com atritos, desnivelamentos e dificuldades de entendimento. Segundo Braga (2010, p. 5), "comunicação não é só aquela de valor alto, do sucedimento precioso e raro - mas toda troca, articulação, passagem entre grupos, entre indivíduos, entre setores sociais - frequentemente desencontrada, conflitiva, agregando interesses de todas as ordens".

Se comunicar não é simplesmente passar informação, por outro lado, a comunicação pode ser confundida com informação. No entanto, há diferença entre cada elemento. "A informação é a mensagem. A comunicação é a relação, que é muito mais complexa" (WOLTON, 2011, p. 12). Para o autor, a comunicação está envolvida na negociação de sentidos entre aqueles que fazem parte dessa situação. Se no ontem, devido à hierarquia das relações humanas, comunicar significava transmitir, "hoje, é quase sempre negociar, pois os indivíduos e os grupos se acham cada vez mais em situação de igualdade" (Ibidem, p. 19). Essa complexidade estaria relacionada à própria incomunicação que se tem atualmente pelo excesso de informação. Aí residiria a necessidade da negociação, na medida que a informação se generalizou, e os públicos se tornaram mais heterogêneos e numerosos.

Sobre comunicação, Wolton (2011) afirma que seus horizontes são o compartilhamento, a convicção, a sedução, a influência, a convivência e a incomunicação, e que envolve três dimensões: "a mais visível e agradável é a tecnológica. A mais complicada, mais lenta para decifrar e operar, é a dimensão cultural. A mais prometedora, com a multiplicação dos contatos e das tecnologias, é a dimensão econômica" (Ibidem, p. 23). Em 
relação à questão da técnica e da tecnologia, o autor defende que o aumento do número de ferramentas não significou necessariamente melhoria das condições de comunicação.

\section{Contratação virtual: uma questão de ubiquidade}

O termo "mídia" foi popularizado e passou a designar o conjunto dos meios de comunicação de massa, sobretudo, a imprensa escrita, as emissoras de rádio e televisão e os sites noticiosos da internet. No entanto, se alargamos a visão a respeito do significado de mídia, vemos que esse termo significa mais. Na origem, "mídia" é uma tradução livre de media, plural de medium ("meio", em latim). Se acompanhamos o pensamento de Marshall Mcluhan, por exemplo, vemos que ele estende a noção de meio a diversas propriedades e realizações do homem, adjetivando-a sob a alcunha de extensão.

Nesse sentido, percebemos que quando abordamos a problemática da ubiquidade midiática discutimos mais que simplesmente a presença na sociedade dos meios de comunicação de massa. Na verdade, falamos da presença difusa de uma série de meios, que não deixam de ser de comunicação, pelo contrário, e que aparecem de forma definida, isto é, voltados a determinados propósitos de realização, ou seja, programados para a execução de tarefas com fins específicos. A ubiquidade midiática representa então esse espalhamento de uma série de meios técnicos e tecnológicos pela sociedade, de forma que as mídias estão presentes em todos os cantos e para os mais diversos fins. Os meios fornecem modos diferentes e singulares de interação na sociedade entre os indivíduos e, além disso, estão construídos para a realização de tarefas que atendam as demandas sociais.

Nesse contexto, um software voltado para a execução de tarefas que ajudam o homem a resolver seus problemas e satisfazer suas necessidades pode ser considerado um meio de comunicação, um medium, principalmente, se percebemos que ele tende tanto a informar como a comunicar a quem o manipula a partir de uma interação que se estabelece pela criação de um vínculo entre homem e máquina. Assim, um conjunto de softwares pode ser percebido como um media ou uma mídia que se presta ao engendramento de uma relação dos sujeitos com o mundo através de uma plataforma comunicacional específica.

A adoção pelo Sport Club Internacional de um conjunto de softwares para o CAPA vem ao encontro da inauguração de uma nova plataforma mediática que transforma a relação dos profissionais do próprio clube com a realidade do futebol. Se antes as contratações eram realizadas a partir do oferecimento de atletas por empresários e o necessário deslocamento de profissionais do clube para observação in loco dos jogadores pretendidos, agora pelo menos parte do trabalho pode ser realizado em Porto Alegre, cidade do clube. Nesse centro, os profissionais do setor contam com dispositivos tecnológicos, 
como computadores e aparelhos de televisão, que agilizam o processo de observação de atletas. Os softwares ganham destaque porque é por meio deles que no CAPA se enxerga melhor o jogador e suas potencialidades, e porque eles oferecem uma série de dados precisos sobre os atletas, o que permite o melhor conhecimento deles por parte de quem analisa as futuras contratações.

Com a concentração do trabalho na computação e nesse tipo de mídia que possibilita outra forma de relação entre clube e mercado do futebol, acaba se inaugurando um novo ambiente. Assim, trabalha-se sobre uma forma de vida digital, em que o mundo dos bits parece ter vida própria sobre o mundo dos átomos. Segundo Negroponte (1995, p. 19), "um bit não tem cor, tamanho ou peso e é capaz de viajar à velocidade da luz. Ele é o menor elemento atômico no DNA da informação. É um estado: ligado ou desligado, verdadeiro ou falso, para cima ou para baixo, dentro ou fora, preto ou branco".

O trabalho acontece, sobretudo, com imagens de alta resolução e definição, na medida em que é por meio delas que o CAPA conduz sua avaliação de atletas. Os bits aparecem como uma chave que possibilita a variação nessa própria atividade de trabalho com a resolução, pois permitem que se guarde uma grande quantia de informações em baixa resolução caso necessário. "Na utilização dos bits para a descrição de sons e imagens, há uma vantagem natural em usá-los na menor quantidade possível. Trata-se de algo relacionado com a conservação de energia" (Ibidem, p. 21).

O que temos no CAPA é um verdadeiro trabalho com recursos de multimídia. Há cerca de 20 anos, Negroponte já tratava sobre a noção de multimídia, ainda que na época a tecnologia não fosse tão avançada quanto nos dias de hoje. Segundo o autor, duas consequências poderiam ser observadas quando os meios de comunicação fossem digitais. Uma delas é que "os bits misturam-se sem qualquer esforço. Começam a mesclar-se e podem ser utilizados e reutilizados em seu conjunto ou separadamente. A mistura de áudio, vídeo e dados é chamada multimídia" (Ibidem, p. 23). Nesse sentido, os computadores do CAPA com seus softwares de última geração podem ser considerados produtos multimídia porque apresentam possibilidade de interação entre homem e máquina e são dotados de recursos de vídeo, a partir de onde se analisam os atletas pretendidos.

A problemática da vida digital é retratada aqui porque uma atividade que antes era exercida por meio da necessária presença de sujeitos em situação de experiência de uma mesma situação acontece agora em uma esfera em que um conjunto de dispositivos coopera com aparelhos de televisão que transmitem em sinal digital e bits que condensam informações a ser analisadas nos softwares. Essa combinação de dispositivos só é possível porque, como lembra Negroponte, o mundo digital é maleável por natureza: “ele pode 
crescer e modificar-se de uma forma mais contínua e orgânica do que os antigos sistemas analógicos" (Ibidem, p. 47).

No trabalho realizado pelos profissionais do CAPA, os dados podem aparecer de formas diversas. Esse autor já assinalava que "uma mensagem pode apresentar vários formatos derivando automaticamente dos mesmos dados" (Ibidem, p. 73) e utiliza o exemplo de uma partida de futebol, o que coincide com o que o Sport Club Internacional faz em seus gabinetes eletrônicos: "Os bits de uma partida de futebol podem ser convertidos pela TV-computador para que você assista ao jogo em forma de vídeo, ouvi-lo na voz de um locutor ou vê-lo em formato de diagramas das jogadas. Em todos esses casos, trata-se do mesmo jogo e do mesmo conjunto de bits" (Ibidem, p. 73 ).

As previsões de Negroponte se tornaram realidade. Hoje, uma simples partida de futebol é fonte de dados que podem ser trabalhados de maneiras diversas; basta um conjunto de dispositivos de comunicação modernos para que se realize um exame apurado de jogadores no mundo do futebol. Não podemos esquecer que esse fato só foi tornado possível porque foram desenvolvidas tecnologias - para parafrasear Michael Dertouzos - centradas no homem. A criação dessas novas ferramentas, como os computadores e seus softwares, contribui para resolver problemas das necessidades humanas.

De acordo com Dertouzos (2002), a computação centrada no homem apresenta forças singulares derivadas de cinco capacidades, que incluem a conversação de sistemas com o homem, a realização de tarefas por esses sistemas, obtenção de informações desejadas, ajuda no trabalho com outras pessoas e adaptação às nossas necessidades individuais. No CAPA essas capacidades se realizam dentro de um contexto específico, a prospecção de atletas visando futuras contratações. Dessas capacidades dos sistemas de computação destacam-se a da obtenção de informações desejadas e a da ajuda no trabalho com outras pessoas. O recolhimento de informações precisas acontece porque os softwares detêm a capacidade de fazer um mapeamento do desempenho dos atletas, fornecendo um raio x completo sobre o perfil deles. De outra forma, a ajuda no trabalho com outros serve como uma espécie de cooperação, em que não se elimina, necessariamente, as formas mais tradicionais de análise dos jogadores, senão se agrega outro modelo de análise em que o mundo digital participa de forma a quantificar qualitativamente o trabalho do conjunto de profissionais encarregados dessa atividade.

O que está em causa são novas formas de colaboração, que envolvem a relação entre pessoas com pessoas e pessoas com máquinas, no caso específico da contratação de jogadores de futebol pelo Internacional a partir da análise destes pelos profissionais do CAPA. Nesse sentido: 
o novo ambiente para o trabalho colaborativo de informação envolve pessoas que deverão estar aptas a se comunicar não só umas com as outras, mas também com as máquinas, através do espaço e do tempo, e em todas as combinações possíveis - pessoas com pessoas, pessoas com máquinas e máquinas com máquinas (Ibidem, p. 122).

Quando olhamos para essa relação entre pessoas e máquinas no CAPA, estamos em um ambiente virtual, que Levy (1999) percebe como potência de atualização de um problema contido no próprio engendramento de um sistema operacional. Conforme o autor, o virtual não se opõe ao real, mas ao atual, já que o virtual é "o complexo problemático, o nó de tendências ou de forças que acompanha uma situação, um acontecimento, um objeto ou uma entidade qualquer, e que chama um processo de resolução: a atualização". Conforme o autor, ela "aparece então como a solução de um problema, uma solução que não estava contida previamente no enunciado" (Ibidem, p. 16).

Os softwares do CAPA operam na virtualização das movimentações dos atletas em partidas de futebol. É um campo problemático que incide sobre a formação da entidade, pois "Virtualizar uma entidade qualquer consiste em descobrir uma questão geral à qual ela se relaciona, em fazer mutar a entidade em direção a essa interrogação e em redefinir a atualidade de partida como resposta a uma questão particular" (Ibidem, p. 18).

\section{Vestimenta eletrônica: uma interface convergente}

Se a tecnologia é usada para a contratação de atletas pelo Internacional, quando os profissionais da bola estão trabalhando no clube não é diferente, o uso dessas ferramentas se mantém. Tanto no CAPA quanto nos treinamentos realizados com os jogadores o objetivo é recolher dados que ajudem a dar um diagnóstico preciso sobre o desempenho dos atletas. No primeiro caso serve para melhorar a impressão dos possíveis futuros jogadores, no segundo caso ajuda a aprimorar o processo de capacitação física do elenco.

Em dias de treinamentos os atletas utilizam uma espécie de colete com GPS que emite sinais para um computador com software, que recebe as informações relativas à movimentação dos jogadores dentro de campo. Com isso, aperfeiçoa-se o próprio deslocamento deles. É uma espécie de vestimenta eletrônica que o departamento de fisiologia do clube utiliza com o objetivo de conhecer melhor o rendimento dos seus profissionais.

Novamente, temos uma cooperação de dispositivos - o colete, um computador, um software, uma antena do GPS - que convergem no fornecimento de informações precisas para quem está à frente do monitor. Dessa forma, há uma relação entre pessoas e máquinas em que todo esse aparato utilizado é uma mediação entre os profissionais que trabalham 
para obter informações na avaliação do desempenho dos atletas em campo e os dispositivos técnicos e tecnológicos que os próprios atletas utilizam para fornecer essas informações.

Há o surgimento de uma interface homem/máquina, que, segundo Levy (1993, p. 176), "designa o conjunto de programas e aparelhos materiais que permitem a comunicação entre um sistema informático e seus usuários humanos". A interface agencia a relação entre os profissionais do clube, os que analisam e os que são submetidos à análise. O conjunto de dispositivos técnico-tecnológicos que se interpõem entre os sujeitos funcionam como uma interface convergente que traduz movimentos humanos em linguagem.

A interface possui sempre pontas livres prontas a se enlaçar, ganchos próprios para se prender em módulos sensoriais ou cognitivos, estratos de personalidade, cadeias operatórias, situações. A interface é um agenciamento indissoluvelmente material, funcional e lógico que funciona como armadilha, dispositivo de captura. Sou captado pela tela, a página, ou o fone, sou aspirado para dentro de uma rede de livros, enganchado a meu computador ou minitel. A armadilha fechou-se, as conexões com meus módulos sensoriais e outros estão estreitas a ponto de fazer-me esquecer o dispositivo material e sentir-me cativado apenas pelas interfaces que estão na interface: frases, história, imagem, música (Ibidem, p. 180).

Em uma ponta do dispositivo temos os computadores e/ou notebooks, em outra ponta o colete. Essas duas interfaces possuem outras interfaces como os softwares e sensores, que acabam conectando-se pelo sistema de GPS que suporta a rede de comunicação que se forma. Por isso, podemos chamar de "dispositivos de convergência", porque trabalham para convergir em uma meta: do levantamento de informações sobre os diferentes tipos de movimentos realizados pelos atletas em campo. Esses dispositivos aparecem acoplados, estando uns dentro dos outros e uns em sequência aos outros. O software aparece dentro do computador e permite a leitura dos dados emitidos pelo colete, assim como os sensores que estão no colete servem para a emissão de informações pela rede. $\mathrm{O}$ computador, a antena do GPS e o colete aparecem como dispositivos em sequência, porque se completam e formam um todo em que as partes estão justapostas. Nesse sentido, "as interfaces são embutidas, dobradas, amarrotadas, deformadas umas nas outras, umas pelas outras, desviadas de suas finalidades iniciais. E isto até o último invólucro, até a última dobra" (Ibidem, p. 182).

No uso dessas tecnologias pela fisiologia do Internacional, a relação com o corpo é fundamental. Há uma relação da tecnologia com o corpo de quem analisa os materiais, mas há, sobretudo, a relação da tecnologia com o corpo de quem utiliza o colete com seus sensores de captação dos movimentos. A tecnologia aparece como meio de extensão dos corpos humanos, de modo que parece que estamos, principalmente no segundo caso, diante de um corpo biocibernético (SANTAELLA, 2004). 
Conforme Santaella (2004), as complementaridades, interfaces e hibridizações do corpo com as tecnologias apresentam uma profusão de aspectos. A autora divide essa profusão em três movimentos: o primeiro que vai de dentro do corpo para fora; o segundo, intersticial, que se localiza entre fora e dentro; e o terceiro que vem de fora do corpo para dentro dele.

Em relação aos dispositivos que são utilizados pelos analistas da fisiologia do Internacional, pode-se dizer que há uma relação de dentro para fora do corpo. "Nesta perspectiva, no seu movimento do interior para o exterior, o corpo biocibernético já teve início com as tecnologias mecânicas da era industrial, cujo paradigma está patente na câmera fotográfica" (Ibidem, p. 58). Embora a autora cite, como exemplo, a câmera fotográfica e sua capacidade extensora de acoplamento à visão, os softwares colocados em funcionamento para a visualização dos sinais e informações emitidos pelos coletes utilizados pelos atletas colaboram no processo de extensão tecnológica do corpo. Eles ampliam o raio de observação dos fenômenos que aparecem, de modo que o corpo entra em um estado de imersão profunda no que está diante de si, nesse caso as informações que emergem na tela do computador.

A própria colocação desse colete com sistema de GPS acoplado com três acelerômetros é uma forma de dar uma extensão tecnológica para o corpo humano, de forma que sejam coletadas amostras precisas do que os jogadores podem produzir de dados a partir de suas movimentações. O homem tem seu corpo aumentado, expandido pelo acoplamento da máquina, de forma que "cada vez mais sofisticadas e sutis, as máquinas estão aptas a estender os músculos, as ondas cerebrais e descargas elétricas do corpo por meio de sensores, eletrodos, dispositivos robóticos, tal como os artistas da era digital vêm explorando" (Ibidem, p. 59).

Ainda que o uso dos coletes pelos atletas do Internacional nos remeta a uma extensão do corpo de dentro para fora, também indica a possibilidade da introjeção do dispositivo em um movimento de fora para dentro, dado o acoplamento da "máquina" ao corpo humano. É claro que não há a invasão do corpo humano literalmente, contudo, há uma espécie de diálogo muito próximo entre máquina e homem, máquina e corpo, na tentativa da tecnologia de extrair do ósseo tudo aquilo que ele pode render em termos de informação: "o movimento de fora para dentro coincide com aquilo que mais comumente recebe o nome de 'ciborgue'. O corpo ciborgue constitui, assim, em uma das vertentes do corpo biocibernético" (Ibidem, p. 61). Há uma penetração que não é invasiva, que “já começa nas tecnologias biomédicas com seus aparelhos de diagnóstico que penetram, de modo não invasivo, em regiões cada vez mais profundas e cada vez menores dos órgãos, tecidos, membranas, células, genes. Os recessos do corpo são virados pelo avesso para serem devolvidos como imagens precisas" (Ibidem, p. 63). 


\section{Considerações finais}

As tentativas de comunicação na sociedade contemporânea acontecem de formas diversas. O uso de tecnologias é uma das facetas desse processo em que se tenta comunicar e informar o homem sobre o próprio homem. Os indivíduos são colocados em relação de convívio com máquinas que passam a fazer parte de seu existir, de modo que já não há mais uma separação entre sujeito e tecnologia. A técnica prevalece como forma de extrair ao máximo de uma realidade individual ou coletiva resultados que sirvam para melhorar o desempenho humano diante de atividades e desafios que lhe são postos a cada dia.

Urge um pensamento que dê conta, em termos comunicacionais, de abarcar as dimensões desse processo no sentido de percebê-lo pelo ângulo da interposição de novas mídias na relação entre os homens, o que nos coloca diante de um desafio epistemológico: a revisitação do significado integral do termo mídia, tão vinculado aos meios de comunicação de massa, mas que no contexto da ubiquidade necessita ser pensado de uma forma mais plural.

Percebemos que a convergência é outra problemática atual e que nos remonta à justaposição, à conexão e à hibridização de tecnologias colocadas em funcionamento para extrair informações de lugares que passaram cada vez mais a ser explorados, como o corpo humano. De alguma forma, a convergência também se relaciona com a questão midiática porque passa a existir uma série de meios que cooperam em um trabalho de exercício da comunicação. Nesse sentido, a convergência nos remete a uma série de agenciamentos em que a técnica prevalece e termina por inaugurar hiperdispositivos de comunicação, em que uma plataforma inteira atua de forma integrada a partir da combinação de partes interconectadas e que cumprem funções específicas.

\section{Referências}

BRAGA, J. L. Nem rara, nem ausente - tentativa. In: ENCONTRO DA COMPÓS, GT EPISTEMOLOGIA DA COMUNICAÇÃO DO XIX. Rio de Janeiro: PUC/RJ, jun. 2010.

DERTOUZOS, M. A revolução inacabada. São Paulo: Futura, 2002.

FERRARA, L. D'A. Comunicar e semiotizar. In: XV ENCONTRO DA COMPÓS, GT EPISTEMOLOGIA DA COMUNICAÇÃO. Bauru: UNESP/SP, junho 2006.

LÉVY, P. As tecnologias da inteligência. Rio de Janeiro: Editora 34, 1993. . O que é o virtual? São Paulo: Editora 34, 1999.

MACHADO, I. Comunicação, um problema semiótico? In: X ENCONTRO DA COMPÓS, GT EPISTEMOLOGIA DA COMUNICAÇÃO. Brasília: UNB/DF, maio-jun. 2001.

NEGROPONTE, N. A vida digital. São Paulo: Companhia das Letras, 1995.

130 Comunicação \& Inovação, PPGCOM/USCS 
SAMPAIO, I. Conceitos e modelos da comunicação. In: X ENCONTRO DA COMPÓS, GT EPISTEMOLOGIA DA COMUNICAÇÃO. Brasília: UNB/DF, maio-jun. 2001.

SANTAELLA, L. Corpo e comunicação: sintoma da cultura. São Paulo: Paulus, 2004.

SANTOS, T.Oacontecimento comunicacional.In:XVIENCONTRODACOMPÓS, GTEPISTEMOLOGIA DA COMUNICAÇÃO. Curitiba: UTP/PR, jun. 2007.

WOLTON, D. Informar não é comunicar. Porto Alegre: Sulina, 2010. 
